\title{
Paralinear Oxidation of CVD SiC in Water Vapor
}

The oxidation kinetics of CVD SiC were monitored by thermogravimetric analysis (TGA) in a $50 \% \mathrm{H}_{2} \mathrm{O} / 50 \% \mathrm{O}_{2}$ gas mixture flowing at $4.4 \mathrm{~cm} / \mathrm{s}$ for temperatures between $1200^{\circ}$ and $1400^{\circ} \mathrm{C}$. Paralinear weight change kinetics were observed as the water vapor oxidized the $\mathrm{SiC}$ and simultaneously volatilized the silica scale. The long-term degradation rate of $\mathrm{SiC}$ is determined by the volatility of the silica scale. Rapid SiC surface recession rates were estimated from these data for actual aircraft engine combustor conditions.

\section{Introduction}

Silicon Carbide-based composites are currently being developed for use in the complex environments of heat engines. Possible degradation mechanisms for $\mathrm{SiC}$ in combustion environments have been reviewed by Jacobson.' While the behavior of $\mathrm{SiC}$ in oxygen has been well studied, less information on the durability of $\mathrm{SiC}$ in more complex combustion environments is available. Some burner rig studies of $\mathrm{SiC}$ degradation have been conducted $;^{2-4}$ however, specific degradation mechanisms are difficult to identify in this type of study since the environmental variables are not well defined and degradation rates are difficult to quantify. Water vapor is a major component of all combustion environments. Jacobson' has calculated that the products of combustion contain about $10 \%$ water vapor independent of the fuel-to-air ratio. In this study, we have attempted to isolate the basic mechanisms of $\mathrm{SiC}$ degradation in water vapor.

In an environment containing water vapor and oxygen, thermodynamic calculations indicate the primary reactions which occur for the oxidation of $\mathrm{SiC}$ are

$$
\begin{aligned}
& \mathrm{SiC}+\frac{3}{2} \mathrm{O}_{2}(g)=\mathrm{SiO}_{2}+\mathrm{CO}(g) \\
& \mathrm{SiC}+3 \mathrm{H}_{2} \mathrm{O}(g)=\mathrm{SiO}_{2}+3 \mathrm{H}_{2}(g)+\mathrm{CO}(g)
\end{aligned}
$$

We report in this paper the first observation that the silica scale formed on $\mathrm{SiC}$ in an oxygen/water vapor gas mixture may simultaneously volatilize by forming a silicon hydroxide or silicon oxyhydroxide species under atmospheric pressures. Some possible volatilization reactions are ${ }^{5}$

$$
\begin{aligned}
& \mathrm{SiO}_{2}+\mathrm{H}_{2} \mathrm{O}(g)=\mathrm{SiO}(\mathrm{OH})_{2}(g) \\
& \mathrm{SiO}_{2}+2 \mathrm{H}_{2} \mathrm{O}(g)=\mathrm{Si}(\mathrm{OH})_{4}(g) \\
& 2 \mathrm{SiO}_{2}+3 \mathrm{H}_{2} \mathrm{O}(g)=\mathrm{Si}_{2} \mathrm{O}(\mathrm{OH})_{6}(g)
\end{aligned}
$$

Silica volatility in water vapor will be discussed in more detail below.

Nathan S. Jacobson--contributing editor

Manuscript No. 192772. Received March 10, 1995; approved July 10, 1996 Work performed in part under NASA cooperative agreement NCC3-205 with Cleveland State University.

'Member, American Ceramic Society.

tResident Research Associate at NASA-Lewis Research Center
The rate of reactions (1) and (2) can be described by a parabolic rate constant, $k_{\mathrm{p}}$. The rate of reactions (3)-(5) are given by linear volatilization constants, $k_{1}$. When oxidation and volatilization occur simultaneously, the oxidation rate is affected by the volatilization rate, and the overall kinetics are described by the more complex paralinear kinetics. ${ }^{6}$

Paralinear oxidation kinetics can be monitored in terms of either changes in oxide thickness or changes in overall sample weight. Paralinear oxide scale thickness kinetics have been mathematically described by Tedmon for $\mathrm{Cr}_{2} \mathrm{O}_{3}$-forming $\mathrm{Fe}-\mathrm{Cr}$ alloys. ${ }^{7}$ This expression is directly applicable to $\mathrm{SiC}$ and is as follows:

$$
t=\frac{k_{\mathrm{p}}^{\prime}}{2 k_{1}^{\prime 2}}\left[-\frac{2 k_{1}^{\prime} x}{k_{\mathrm{p}}^{\prime}}-\ln \left(1-\frac{2 k_{1}^{\prime} x}{k_{\mathrm{p}}^{\prime}}\right)\right]
$$

where $t$ is the oxidation time, $x$ is the oxide thickness, $k_{\mathrm{p}}^{\prime}$ is the parabolic rate constant for oxidation in units of thickness ${ }^{2}$ per unit time, and $k_{1}^{\prime}$ is the linear rate constant for scale volatilization in units of thickness/time. At long times, the scale thickness becomes a constant as the oxidation rate equals the volatilization rate. This limiting scale thickness, $x_{\mathrm{f}}$, is equal to $k_{\mathrm{p}}^{\prime} / 2 k_{1}^{\prime}$. The oxide thickness as a function of time as predicted by Eq. (6) is shown in Fig. 1 for typical values of $k_{\mathrm{p}}^{\prime}$ and $k_{1}^{\prime}$.

Similarly, paralinear kinetics for oxidation of $\mathrm{SiC}$ can be expressed in terms of measured weight changes ${ }^{6}$ using the following two expressions:

$$
\begin{aligned}
& t=\frac{\alpha^{2} k_{\mathrm{p}}}{2 k_{1}^{2}}\left[-\frac{2 k_{1} \Delta w_{1}}{\alpha k_{\mathrm{p}}}-\ln \left(1-\frac{2 k_{1} \Delta w_{1}}{\alpha k_{\mathrm{p}}}\right)\right] \\
& \Delta w_{2}=-\beta k_{1} t
\end{aligned}
$$

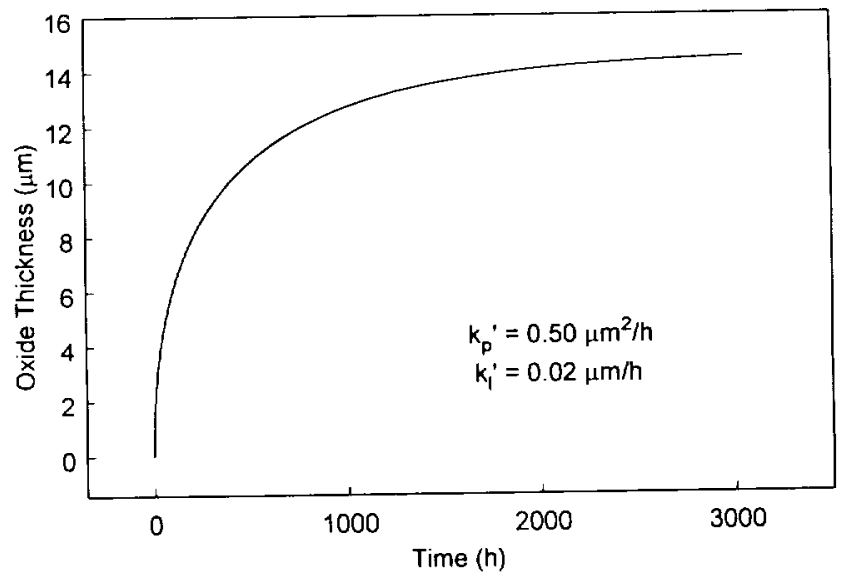

Fig. 1. Paralinear oxide growth kinetics typical for $\mathrm{SiC}$ in $50 \%$ water vapor flowing at $4.4 \mathrm{~cm} / \mathrm{s}$ and temperatures between $1200^{\circ}$ and $1400^{\circ} \mathrm{C}$. The curve is a graphical representation of Eq. (6). After about $3000 \mathrm{~h}$, a limiting oxide thickness equal to $k_{p}^{\prime} / 2 k_{1}^{\prime}$ is achieved. 
where $\Delta w_{1}$ is the weight gain due to growth of the scale, $\Delta w_{2}$ is the weight loss of the scale due to volatilization, $k_{\mathrm{p}}$ is the parabolic rate constant for oxidation in units of mass ${ }^{2} / \mathrm{area}^{2}$ time, $k_{1}$ is the linear rate constant for $\mathrm{SiO}_{2}$ volatilization in units of mass/area time, $\alpha=\mathrm{MW}_{\mathrm{SiO}_{2}} /\left(\mathrm{MW}_{\mathrm{O}_{2}}-\mathrm{MW}_{\mathrm{C}}\right)$, and $\beta=M W_{\mathrm{SiC}} / \mathrm{MW}_{\mathrm{SiO}_{2}}$ where $\mathrm{MW}$ is the molecular weight of the species shown in subscript. The total observed weight change is the sum of $\Delta w_{1}$ and $\Delta w_{2}$. At long times when the limiting oxide scale thickness is achieved, the weight change is simply expressed by Eq. (8). The weight changes for $\mathrm{SiC}$ in $50 \%$ $\mathrm{H}_{2} \mathrm{O} / 50 \% \mathrm{O}_{2}$ predicted by Eqs. (7) and (8), as well as their sum, are shown in Fig. 2 for typical values of $k_{\mathrm{p}}$ and $k_{1}$. These rate constants, though expressed in terms of weight change rather than oxide thickness, are equivalent to those used in Fig. 1. Since the abscissa is the same in Figs. 1 and 2, direct comparisons of oxide thickness and weight change at any given time can be made. Note that the weight loss is nearly linear at times well before scale growth and vaporization rates balance one another and the limiting oxide thickness is achieved.

Some information on both the parabolic and linear rate constants is found in the literature and will now be summarized. The parabolic oxidation rate of silicon carbide in oxygen by reaction (1) has been extensively studied. ${ }^{8.9}$ The parabolic oxidation of silicon carbide in water vapor has also been studied but is somewhat less understood. A summary of these studies is given in Ref. 10. While these studies in general show the rate of oxidation is enhanced in water vapor, a systematic study of the dependence of the oxidation rate on water vapor partial pressure has not yet been completed. However, it has been shown that in $\mathrm{H}_{2} \mathrm{O} / \mathrm{O}_{2}$ gas mixtures, water vapor is the primary oxidant for $\mathrm{Si}$." It has also been shown that the parabolic oxidation rate is proportional to the water vapor partial pressure for $\mathrm{Si}$, " and preliminary results indicate the same holds true for $\mathrm{SiC}^{.12}$

The oxidation/volatilization of $\mathrm{SiC}$ has been reported by $\mathrm{Kim}$ and Readey ${ }^{13}$ and Narushima et al.$^{14}$ in cases where $\mathrm{H}_{2} / \mathrm{H}_{2} \mathrm{O}$ or $\mathrm{CO} / \mathrm{CO}_{2}$ gas mixtures are used. In these cases the oxide is reduced by hydrogen or $\mathrm{CO}$ to form the volatile $\mathrm{SiO}$ species. In the work by Kim and Readey, the minimum hydrogen partial pressure was 0.9 atm. It must be emphasized that in our work the maximum hydrogen partial pressure from the decomposition of water was $10^{-5}$ atm. Thermodynamic calculations show that $\mathrm{SiO}$ is not present in large enough quantities to account for the observed silica volatility in the oxidizing conditions studied here; therefore, some other volatile species must account for the observed paralinear kinetics.

The volatility of free-standing silica in high pressure (on the order of $100 \mathrm{~atm}$ ) water vapor has been known for some time and is summarized by Glemser and Wendlandt. ${ }^{15}$ It has been proposed that volatilization of silica under these conditions

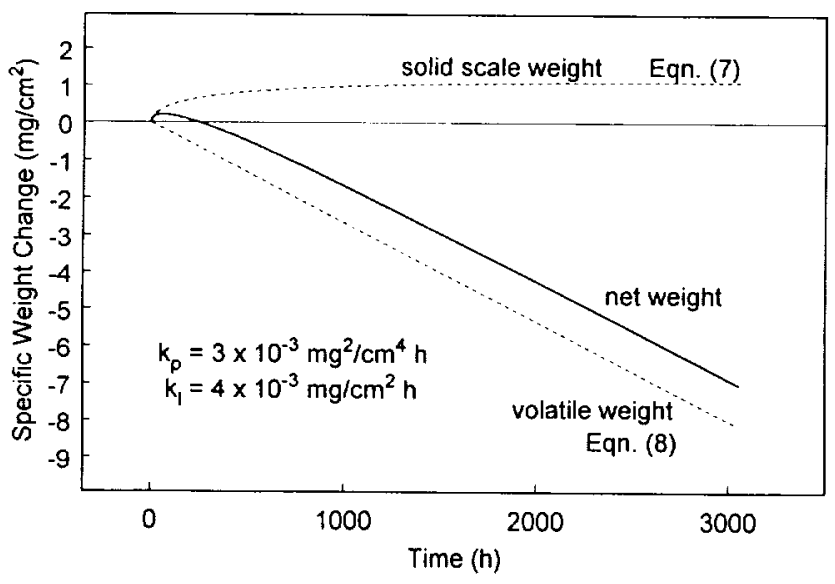

Fig. 2. Paralinear weight change kinetics typical for $\mathrm{SiC}$ in $50 \%$ water vapor flowing at $4.4 \mathrm{~cm} / \mathrm{s}$ and temperatures between $1200^{\circ}$ and $1400^{\circ} \mathrm{C}$. The dotted curves are from Eqs. (7) and (8), while the solid curve represents the total weight change expected. occurs by reactions (4) and (5). Other work by Cheng and Cutler $^{16}$ and Hashimoto ${ }^{17}$ has shown that silica is also volatile in atmospheric pressures of water vapor. The careful transpiration study by Hashimoto ${ }^{17}$ shows a square dependence of the volatility rate on water vapor pressure, indicating that reaction (4) is dominant. The likely volatile species under these conditions is thus $\mathrm{Si}(\mathrm{OH})_{4}$. Preliminary mass spectrometric results at atmospheric pressures confirm the presence of this vapor species. ${ }^{18}$ Finally at very low water vapor pressures, $10^{-5} \mathrm{~atm}$, a Knudsen cell mass spectrometric study by Hildenbrand and $\mathrm{Lau}^{19}$ has identified $\mathrm{SiO}(\mathrm{OH})_{2}$ as the volatile species, indicating that reaction (3) may be important under these conditions.

The idea of simultaneous volatilization of silica formed during oxidation of silica-forming materials $\left(\mathrm{Si}, \mathrm{SiC}, \mathrm{Si}_{3} \mathrm{~N}_{4}\right)$ in water vapor/oxygen gas mixtures follows naturally from the above volatility studies of free-standing silica, yet there are very few observations of this in the literature. The volatility of silica formed as an oxidation product on silicon above 25 -atm water vapor pressure has been noted in the literature. ${ }^{20}$ Some evidence of the erosion of silica thermally grown on silicon in $1 \mathrm{~atm}$ wet oxygen $\left(83 \% \mathrm{H}_{2} \mathrm{O}\right)$ and steam was observed. ${ }^{21}$

The objectives of this paper are, first, to demonstrate conclusively that paralinear oxidation of $\mathrm{SiC}$ does occur in water vapor. Once this has been demonstrated, the second major objective of this work is to accurately determine the silica linear volatilization rate constant in water vapor. Finally, the volatilization rate will be used to predict the long-term durability of $\mathrm{SiC}$ in combustion environments.

\section{Experimental Procedure}

\section{(I) Material}

The material used in this study was polycrystalline monolithic CVD $\beta$-SiC (Raytheon/Bomass Machine Specialties, Somerville, MA). The major impurities as determined by semiquantitative $\mathrm{dc}$ arc spectrographic emission were $\mathrm{Be}$ and $\mathrm{Cu}$, both in quantities of less than $100 \mathrm{ppm}$. The sample coupons had dimensions of approximately $2.5 \times 0.7 \times 0.3 \mathrm{~cm}$ and had a 600 grit surface finish. Some experiments were also conducted with fused quartz coupons (Quartz Scientific, Fairport, $\mathrm{OH})$. Manufacturer's specifications state that this material has a nominal purity of $99.995 \%$. These sample coupons had dimensions of approximately $2.5 \times 1.2 \times 0.1 \mathrm{~cm}$. All samples were ultrasonically cleaned in detergent, deionized water, acetone, and alcohol prior to furnace exposures.

\section{(2) Thermogravimetric Experiments (TGA)}

The durability of $\mathrm{SiC}$ in water vapor was studied between $1200^{\circ}$ and $1400^{\circ} \mathrm{C}$. Initial studies of $\mathrm{SiC}$ had been conducted in a $10 \% \mathrm{H}_{2} \mathrm{O}$ /balance $\mathrm{O}_{2}$ gas mixture ${ }^{10}$ which is close to the water vapor level found in the combustion products at 1 atm. Little effect of $\mathrm{H}_{2} \mathrm{O}$ vapor at this level was found on the oxidation of $\mathrm{SiC}$. It was thought that a $50 \% \mathrm{H}_{2} \mathrm{O} / 50 \% \mathrm{O}_{2}$ gas mixture at 1 atm total pressure would more realistically simulate combustion conditions which are typically at higher pressures (e.g., $10 \% \mathrm{H}_{2} \mathrm{O}$ at 5 atm total pressure). At the low flow rates typically used in TG studies, $0.4 \mathrm{~cm} / \mathrm{s}$, the water vapor saturation level in the gas stream was found to be less than $50 \%$ even with the water bath temperature at the desired dewpoint of $81.7^{\circ} \mathrm{C}$. Surprisingly, at a constant bath temperature as the flow rate was increased, the saturation level also increased. A total flow rate of $4.4 \mathrm{~cm} / \mathrm{s}$ was used to obtain $50 \%$ saturation of the oxygen stream. The highest water vapor partial pressure that was reproducibly obtained using the water saturator already described ${ }^{10}$ was $0.5 \mathrm{~atm}$. Fortuitously enough, use of a higher flow rate led to the observation of silica volatility.

Three types of thermogravimetric experiments were conducted to determine the parabolic oxidation rate $\left(k_{\mathrm{p}}\right)$ and linear volatilization rate $\left(k_{1}\right)$ constants, as explained below. In all cases, samples were weighed before and after each TGA experiment. First, a cleaned as-received SiC coupon was suspended from a microbalance (Cahn 1000, Cahn Instruments, Cerritos, CA) using a sapphire hanger. The samples were suspended 
within a $2.2 \mathrm{~cm}$ ID fused quartz reaction tube (Quartz Scientific). Fused quartz reaction tubes were used, since previous work had shown that the use of high-purity alumina tubes with water vapor substantially increased $k_{\mathrm{p}}$ for $\mathrm{SiC},{ }^{10}$ due to residual volatile $\mathrm{Na}$ impurities. The samples were heated using a $\mathrm{MoSi}_{2}$ furnace. The hot zone of this furnace was about 4 in. $(\sim 10.2 \mathrm{~cm})$ long. The sample temperature was calibrated to the furnace setpoint in separate experiments, using a type $R$ thermocouple. The thermocouple was removed during experiments with sample coupons to avoid contamination from the alumina thermocouple sheath. The temperature uncertainty is $\pm 5^{\circ} \mathrm{C}$. A gas mixture of $50 \% \mathrm{O}_{2} / 50 \% \mathrm{H}_{2} \mathrm{O}$ flowed through the reaction tube at a room temperature rate of $1 \mathrm{~L} / \mathrm{min}(4.4 \mathrm{~cm} / \mathrm{s})$. A counter flow of $0.4 \mathrm{~L} / \mathrm{min}$ dry argon was circulated through the balance chamber to prevent water condensation in the microbalance. Gas flow was controlled using a Tylan mass flow system. Water content of the gas stream was monitored by measuring the condensate in the gas exhaust daily and was very constant. Weight and time were recorded every $6 \min$ for $100 \mathrm{~h}$, using a data acquisition system. Equations (7) and (8) were fit to the resulting specific weight-vs-time curve, using the procedure described below. The rate constants $k_{\mathrm{p}}$ and $k_{1}$ were obtained from the best-fit curve.

A second experiment was conducted to directly obtain the linear volatilization rate of silica, $k_{1}$, under the same conditions. A fused quartz coupon was exposed to the water vapor/oxygen gas mixture, using the same TGA procedure as described in the previous paragraph. A linear weight loss uncomplicated by the oxidation reaction for $\mathrm{SiC}$ was obtained. The rate constant, $k_{1}$, was determined from the final weight minus the initial weight and was in good agreement with the rate determined from a linear regression of the weight loss data.

A third type of thermogravimetric experiment was also conducted to determine the linear volatilization rate constant. Here, the $\mathrm{SiC}$ was preoxidized to grow a thick oxide scale $(6$ to $8 \mu \mathrm{m})$. Ideally, a preoxidation exposure in dry oxygen in the TGA would be the simplest procedure. However, the time required to grow a thick oxide in this manner is inordinately long. Since water vapor enhances the oxidation rate of $\mathrm{SiC}$, it was found that a thick oxide scale could be grown more rapidly in a horizontal tube furnace in $50 \% \mathrm{H}_{2} \mathrm{O} / 50 \% \mathrm{O}_{2}$ in which conditions were such that the gas stream was saturated with the silicon hydroxide species, thus suppressing the silica volatility. This preoxidation procedure was conducted simultaneously for four coupons and is described in detail elsewhere. ${ }^{12}$ After preoxidation, an approximate oxide thickness for each sample was determined from the weight change. One sample from each preoxidation batch was cross-sectioned to measure the oxide thickness by SEM. No oxide spalling was observed. Each intact sample was inserted into the TGA and exposed to the $50 \%$ water vapor mixture. During this exposure to water vapor, the weight gain due to oxidation was negligible compared to the linear weight loss of the silica scale. The rate constant, $k_{1}$, was determined from a linear regression of the weight loss data.

\section{(3) TGA Control Experiments}

Fused quartz coupons were exposed to $100 \%$ dry $\mathrm{O}_{2}$ in the TGA under identical conditions $\left(1200^{\circ}-1400^{\circ} \mathrm{C}, 4.4 \mathrm{~cm} / \mathrm{s}\right.$ total flow) to ensure that any volatility effects were due to the water vapor effects only. No weight change was observed in these experiments.

There was concern that volatility of the fused quartz reaction tube would affect the oxidation kinetics of the SiC. Two specific issues were of concern. First, there was evidence that silica was depositing from the vapor phase on the sapphire hanger during the TGA exposure. Control experiments in $50 \%$ water vapor/ $50 \%$ oxygen mixtures were therefore conducted. Sapphire hangers were suspended in the hot zone without samples and exposed to the water vapor/oxygen mixture at temperature. The TGA results show that linear weight gains were observed as volatiles from the fused quartz tube deposited on the portion of the hanger that was relatively cool. These deposits were identified as silica, based on EDS results which showed silicon and oxygen. The linear weight gain rate was $(1.37 \pm 0.55) \times$ $10^{-2} \mathrm{mg} / \mathrm{h}^{\ddagger}$ for six control experiments independent of temperature between $1200^{\circ}$ and $1400^{\circ} \mathrm{C}$. The weight gains of the control runs were also in agreement with the difference between the TGA $\Delta w t$ and the $\Delta w t$ measured from the coupon before and after exposure, which was assumed to be linear and averaged $(1.74 \pm 0.33) \times 10^{-2} \mathrm{mg} / \mathrm{h}^{\ddagger}$ for 19 experiments of all experiment types involving test coupons. Linear weight gains based on the weight difference technique were subtracted from the raw TGA data obtained for each coupon.

The second concern was that the volatility of the fused quartz tube would affect the volatility of the test coupon. If $\mathrm{Si}-\mathrm{OH}$ vapor species from the fused quartz tube saturated the gas stream before reaching the test coupon, volatility of the silica forming on the $\mathrm{SiC}$ coupon would be partially or completely suppressed. Therefore, the test coupon was placed near the upstream edge of the hot zone so that most of the volatile area of the tube would be downstream of the sample. The gas would have little time to be saturated with $\mathrm{Si}-\mathrm{OH}$ species before reaching the test coupon.

\section{(4) Characterization Techniques for Oxidized Coupons}

Oxide thicknesses for each coupon were measured in cross section by scanning electron microscopy (SEM). Oxides were polished off one edge of each coupon using a $15 \mu \mathrm{m}$ diamond wheel. Oxide thicknesses were measured approximately every millimeter along the edge of the coupon, giving about 25 total thickness measurements for each coupon. The accuracy of these thickness measurements was within $7 \%$ of the true thickness, based on calibration with an NBS SEM magnification standard. Some test coupons were also examined for surface morphology by SEM and phase composition by $\mathrm{X}$-ray diffraction analysis (XRD).

\section{(5) Paralinear Weight Change Data Analysis Methods}

The kinetic rate constants $k_{\mathrm{p}}$ and $k_{1}$ for each paralinear data set were determined by nonlinear least-squares analysis and the paralinear kinetic model described in the Introduction. The objective function, $\chi$, to be minimized was ${ }^{22}$

$$
\chi^{2}\left(k_{\mathrm{p}}, k_{\mathrm{i}}\right)=\sum_{i=1}^{N} \frac{\Delta w_{i}^{\text {obs }}-\Delta w^{\text {calc }}\left(t_{i}^{\prime} ; k_{\mathrm{p}}, k_{1}\right)}{\sigma_{\mathrm{i}}}
$$

where $\Delta w_{i}^{\text {obs }}$ is the experimentally observed specific weight change measured at time $t_{\mathrm{i}}$ during the TGA run. The quantity $\Delta w^{\text {calc }}\left(t_{i}^{\prime} ; k_{\mathrm{p}}, k_{1}\right)$ is the specific weight change calculated from the paralinear kinetic model for time $t_{\mathrm{i}}$. The variance, $\sigma_{i}$, was assigned a value of unity, since the true values associated with the experimental data were not known a priori.

The quantity $\Delta w^{\text {calc }}\left(t_{i} ; k_{\mathrm{p}}, k_{1}\right)$ is given by the relationship

$$
\Delta w_{\mathrm{i}}^{\text {calc }}=\Delta w_{1_{\mathrm{i}}}+\Delta w_{2_{1}}
$$

The quantities $\Delta w_{1}$ and $\Delta w_{2}$ are given by Eqs. (7) and (8), respectively. The differential form of Eq. (7) was used to compute $\Delta w_{1}$ by approaching the solution as an initial value problem and then applying a 4th order Runge-Kutta integration technique ${ }^{22}$ to solve for $\Delta w_{1}$ at time $t_{i}$. Minimization of the objective function, $\chi^{2}\left(k_{p}, k_{1}\right)$ was accomplished by simultaneous adjustment of $k_{\mathrm{p}}$ and $k_{1}$ using the Levenberg-Marquardt technique.22

The statistical uncertainties associated with the $k_{\mathrm{p}}$ and $k_{1}$ estimates were determined by the "bootstrap" method, ${ }^{22,23}$ a Monte Carlo-based simulation technique. In this method, the probability distributions associated with the estimated kinetic parameters may be reproduced from the original experimentally obtained data set by randomly resampling the original data set along with data point replacement. ${ }^{23}$ This technique has been successfully used in many scientific disciplines ranging from astrophysics ${ }^{24}$ to elementary particle physics, ${ }^{25}$ as well as materials science. ${ }^{26}$

\footnotetext{
tUncertainties reported are $1 \sigma$
} 
The generation of synthetic data sets in the bootstrap method consists of randomly selecting $N$ data points from the original data set, $R_{(0)}=\left\{p_{1}, \ldots, p_{N}\right\}$, and then placing each randomly selected point into the $N$-membered set, $R_{(1)}$. Once the random selection is complete, $R_{(1)}$ is now a subset of $R_{(0)}$ containing members of $R_{(0)}$ which are replicated with a probability of $\approx 1 / e$ in $R_{(1)}$. Therefore, $R_{(1)}$ will contain some members of $R_{(0)}$ which now will appear more than once while other members of $R_{(0)}$ will be absent in $R_{(1)}$. This process is repeated $M$ times to produce $M$ synthetic data sets.

Each of the synthetic data sets were subjected to nonlinear least-squares analysis where $M$ values of $k_{\mathrm{p}}^{(\mathrm{B})}$ and $k_{1}^{(\mathrm{B})}$ estimates were obtained. The mean and standard uncertainties were computed from the bootstrap estimates by the respective relations

$$
\bar{k}_{(\mathrm{p}, \mathrm{l})}=\frac{1}{M} \sum_{j=1}^{M} k_{(\mathrm{p}, \mathrm{l})_{\mathrm{i}}}
$$

and

$$
\sigma_{\left(k_{\mathrm{p}}, k_{1}\right)}=\sqrt{\frac{1}{M-1} \sum_{i=1}^{M}\left(k_{(\mathrm{p}, 1)_{i}}-\bar{k}_{(\mathrm{p}, 1)}\right)^{2}}
$$

For typical production runs, $M=200$. However, to determine if the estimated uncertainties determined by the bootstrap method were normally distributed, runs with $M=400$ were performed.

\section{(6) Calculations of Flux of Volatile Species}

The flux of the volatile species under different conditions can be calculated as follows. The flux of a volatile species through a gaseous boundary layer under laminar flow conditions over a flat plate, $J$, can be calculated using the following relationship: ${ }^{27}$

$$
J=0.664\left(\frac{\rho^{\prime} v L}{\eta}\right)^{1 / 2}\left(\frac{\eta}{\rho^{\prime} D}\right)^{1 / 3} \frac{D \rho}{L}
$$

where $v$ is the linear gas velocity, $L$ is the sample length parallel to the flow direction, $\eta$ is the gas viscosity, $D$ is the interdiffusion coefficient for the diffusing species in the major gas species, $\rho$ is the concentration of the diffusing gas species at the solid gas interface, and $\rho^{\prime}$ is the concentration of the major gas species. The gas concentrations are calculated using the ideal gas law. The interdiffusion coefficient was calculated using Chapman-Enskog theory. ${ }^{28}$ Gas viscosities and Leonard-Jones parameters were obtained from the compilation of Svehla. ${ }^{29}$ Since these parameters are not available for $\mathrm{Si}(\mathrm{OH})_{4}$, values for $\mathrm{SiF}_{4}$ were used as an approximation instead.

Under conditions where gas velocities are high, turbulent flow occurs rather than laminar flow. The boundary layer is swept away and increased volatility rates are observed. In the extreme case where no boundary layer is formed, the maximum mass flux of the volatile species, $J$, due to free evaporation into a vacuum is given by the Langmuir equation:

$$
J=P \sqrt{\frac{M}{2 \pi R T}}
$$

where $P$ is the equilibrium vapor pressure of the volatile species, $M$ is the molecular weight of the volatile species, $R$ is the gas constant, and $T$ is the absolute temperature. Equations (13) and (14) thus describe the minimum and maximum possible flux of volatile species.

\section{Results}

\section{(1) Weight Gain and Scale Growth}

A summary of the weight gain (measured before and after TGA experiments) and oxide thickness results for the oxidation of as-received $\mathrm{SiC}$ coupons is shown in Table I. There is poor reproducibility for both the weight gain and oxide thickness at each temperature. Experimental variations of sample properties, temperature, gas flow rate, and water content of the gas stream cannot explain this scatter. The high gas flow rates
$(4.4 \mathrm{~cm} / \mathrm{s})$ increased the amplitude of the noise in the TGA traces but did not affect the accuracy of the measured weight changes. Two possible contributions to this scatter are as follows. Subtraction of the linear rate of silica deposition on the hanger from the overall weight change is a source of error in the calculated rate constants. The magnitude of this uncertainty has already been reported in the section on TGA control experiments. Another source of variability in the volatility rate among the sample coupons under otherwise identical conditions may be the differences in position in the hangdown tube. Positions off of true center of the small-diameter reaction tubes may result in interactions between the gas boundary layers of the sample and the tube wall. This would result in variations in the gas velocity and ultimately variations in the volatility rate from experiment to experiment.

Besides the scatter in the weight gain and oxide thickness among the coupons, there was also a clear discrepancy between the weight gain and oxide thickness for any given coupon, as shown in Table I. For oxidation without volatilization, the weight gain and oxide thickness can be converted using the expressions

$$
\begin{aligned}
& \Delta w t \times 12.9=x \text { for cristobalite } \\
& \Delta w t \times 13.6=x \text { for amorphous silica }
\end{aligned}
$$

where $\Delta w t$ is in $\mathrm{mg} / \mathrm{cm}^{2}$ and $x$ is in $\mu \mathrm{m}$. These expressions already account for weight loss due to $\mathrm{CO}$ formation during oxidation. The uncertainty of thickness results based on SEM measurements will typically be $\pm 10 \%$. The variation in oxide thickness along the length of each coupon is greater than the uncertainty due to the technique. In this study, at $50 \%$ water vapor it was found that the ratio (measured $\Delta \mathrm{wt} / \mathrm{predicted} \Delta \mathrm{wt}$ from the measured oxide cross sections) varied between 0.09 and 0.87 , as shown in Table I. In all cases, the measured oxide thickness was greater than that predicted from the weight gains. In contrast, in previous work conducted in dry oxygen and $10 \%$ water vapor, ${ }^{10}$ it was found that the ratio of the measured $\Delta w t$ to predicted $\Delta w t$ from the above expressions and the measured oxide cross sections varied from 0.96 to 1.27 . These data have not been reported before and are summarized in Table II. In $10 \% \mathrm{H}_{2} \mathrm{O}$ and in dry oxygen, the agreement was good between measured weight gains and the measured oxide thicknesses. If anything, converting from scale thickness to expected weight changes slightly underpredicted the weight gain.

The values of $k_{\mathrm{p}}$ in $50 \%$ water vapor obtained from the fit of the paralinear data to the model are listed in Table III. These values are in fair agreement with values obtained by other methods ${ }^{10.12}$ that are available at this same water vapor partial pressure, as shown in Fig. 3. Values extrapolated from Ref. 10 are obtained by multiplying by five the results which were obtained in $10 \%$ water vapor. This is done because preliminary results show that $k_{\mathrm{p}}$ is approximately proportional to $P\left(\mathrm{H}_{2} \mathrm{O}\right) .^{12}$ The values from Ref. 12 were obtained in $50 \%$ water vapor under conditions where silica volatility did not occur. In this study, an activation energy for the oxidation of $\mathrm{SiC}$ in water vapor of $35 \pm 147 \mathrm{~kJ} / \mathrm{mol}$ (95\% confidence interval) was obtained. Though the uncertainty is large, this result is not statistically significantly different from the value of $41 \mathrm{~kJ} / \mathrm{mol}$ obtained in Ref. 10 , the value of $62 \mathrm{~kJ} / \mathrm{mol}$ obtained in Ref. 12 , and the value of $68 \mathrm{~kJ} / \mathrm{mol}$ obtained by Deal and Grove for the oxidation of silicon in water vapor."

\section{(2) Weight Loss and Scale Volatility}

The weight loss rates for both the fused quartz coupons and preoxidized $\mathrm{SiC}$ coupons were more reproducible than those obtained from the fit of the paralinear weight change of as-received $\mathrm{SiC}$ coupons. Linear volatilization rate constants were taken from the final minus initial weight for the fused quartz coupons and from the linear regression of the weight loss data for the preoxidized $\mathrm{SiC}$ coupons. The weight loss for the first 20 to $30 \mathrm{~h}$ was typically not linear in the experiments involving the preoxidized $\mathrm{SiC}$ coupons and was not included in the linear regression. 
Table I. Comparison of the Total Weight Change, $\Delta$ wt, and the Oxide Thickness, $x$, for the Paralinear Oxidation of $\mathrm{SiC}$ in $50 \% \mathrm{H}_{2} \mathrm{O} / 50 \% \mathrm{O}_{2}$ at $4.4 \mathrm{~cm} / \mathrm{s}^{*}$

\begin{tabular}{cccccc}
\hline $\begin{array}{c}\text { Temp } \\
\left({ }^{\circ} \mathrm{C}\right)\end{array}$ & $\begin{array}{c}\text { Time } \\
(\mathrm{h})\end{array}$ & $\begin{array}{c}\Delta w t \\
\left(\mathrm{mg} / \mathrm{cm}^{2}\right)\end{array}$ & $\begin{array}{c}x^{\dagger} \\
(\mu \mathrm{m})\end{array}$ & $\begin{array}{c}\Delta w t \\
\text { from } x\end{array}$ & $\begin{array}{c}\Delta w t \text { exp/swt } \\
\text { from } x\end{array}$ \\
\hline 1200 & 100 & 0.113 & $2.52 \pm 0.45$ & 0.185 & 0.61 \\
& 100 & 0.226 & $4.21 \pm 0.36$ & 0.309 & 0.73 \\
& 100 & 0.214 & $3.90 \pm 0.57$ & 0.286 & 0.75 \\
& 100 & $0.192^{\ddagger}$ & Missing & & \\
& 115 & 0.018 & $2.72 \pm 0.55$ & 0.199 & 0.09 \\
& 98 & $0.059^{\ddagger}$ & $2.98 \pm 0.53$ & 0.219 & 0.27 \\
1300 & 100 & $0.229^{\ddagger}$ & $4.23 \pm 0.65$ & 0.327 & 0.70 \\
& 100 & $0.152^{\ddagger}$ & $3.68 \pm 0.47$ & 0.284 & 0.54 \\
& 100 & $0.205^{\ddagger}$ & $3.04 \pm 0.54$ & 0.235 & 0.87 \\
& 100 & 0.243 & $4.50 \pm 0.67$ & 0.349 & 0.70 \\
& 100 & 0.271 & $4.42 \pm 0.54$ & 0.342 & 0.79 \\
& 100 & $0.050^{\ddagger}$ & $3.31 \pm 0.73$ & 0.256 & 0.20 \\
& 100 & $0.081^{\ddagger}$ & $4.36 \pm 1.02$ & 0.337 & 0.24 \\
\hline
\end{tabular}

${ }^{*}$ Conversion from $x$ to 4 wt assumes density of amorphous silica at $1200^{\circ} \mathrm{C}\left(2.2 \mathrm{~g} / \mathrm{cm}^{\prime}\right)$ and density of crisiobalite at $1300^{\circ}$ and $1400^{\circ} \mathrm{C}\left(232 \mathrm{~g}^{\circ} \mathrm{cm}^{3}\right){ }^{+}$Uncertainties reported for oxide thicknesses are $1 \sigma$ for at least 20 measurements at $1 \mathrm{~mm}$ spacing along the SiCloxide cross section. Flndicates samples which correspond to paralinear fits listed in Tables III and IV.

Table II. Comparison of the Total Weight Change, $\Delta w t$, and the Oxide Thickness, $x$, for the Parabolic Oxidation of $\mathrm{SiC}$ in $10 \% \mathrm{H}_{2} \mathrm{O} / 90 \% \mathrm{O}_{2}$ and Dry $\mathrm{O}_{2}$ at $0.4 \mathrm{~cm} / \mathrm{s}^{*,+}$

\begin{tabular}{|c|c|c|c|c|c|}
\hline $\begin{array}{l}\text { Temp } \\
\left({ }^{\circ} \mathrm{C}\right)\end{array}$ & $\begin{array}{c}\text { Time } \\
\text { (h) }\end{array}$ & $\begin{array}{c}\Delta w t \\
\left(\mathrm{mg} / \mathrm{cm}^{2}\right)\end{array}$ & $\begin{array}{c}x^{\ddagger} \\
(\mu \mathrm{m})\end{array}$ & $\begin{array}{c}\Delta w t \\
\text { from } x\end{array}$ & $\begin{array}{l}\Delta w t \exp / \Delta w t \\
\quad \text { from } x\end{array}$ \\
\hline 1200 & $\begin{array}{r}97 \\
120 \\
136\end{array}$ & $\begin{array}{l}0.164 \\
0.193 \\
0.212\end{array}$ & $\begin{array}{r}10 \% \mathrm{H}_{2} \mathrm{O} / 90 \% \mathrm{O}_{2} \\
1.90 \pm 0.23 \\
2.07 \pm 0.50 \\
2.33 \pm 0.45\end{array}$ & $\begin{array}{l}0.139 \\
0.152 \\
0.171\end{array}$ & $\begin{array}{l}1.18 \\
1.27 \\
1.24\end{array}$ \\
\hline 1300 & $\begin{array}{l}113 \\
112 \\
117\end{array}$ & $\begin{array}{l}0.211 \\
0.214 \\
0.189\end{array}$ & $\begin{array}{l}2.47 \pm 0.27 \\
2.82 \pm 0.41 \\
2.47 \pm 0.46\end{array}$ & $\begin{array}{l}0.191 \\
0.218 \\
0.191\end{array}$ & $\begin{array}{l}1.11 \\
0.98 \\
0.99\end{array}$ \\
\hline 1400 & $\begin{array}{l}113 \\
112 \\
115\end{array}$ & $\begin{array}{l}0.201 \\
0.191 \\
0.199\end{array}$ & $\begin{array}{l}2.61 \pm 0.29 \\
2.56 \pm 0.19 \\
2.64 \pm 0.57\end{array}$ & $\begin{array}{l}0.202 \\
0.198 \\
0.204\end{array}$ & $\begin{array}{l}1.00 \\
0.96 \\
0.98\end{array}$ \\
\hline $\begin{array}{l}1200 \\
1300 \\
1400\end{array}$ & $\begin{array}{l}115 \\
112 \\
112\end{array}$ & $\begin{array}{l}0.128 \\
0.152 \\
0.163\end{array}$ & $\begin{array}{l}\text { Dry } \mathrm{O}_{2} \\
1.76 \pm 0.45 \\
1.83 \pm 0.34 \\
1.87 \pm 0.30\end{array}$ & $\begin{array}{l}0.129 \\
0.141 \\
0.145\end{array}$ & $\begin{array}{l}0.99 \\
1.08 \\
1.12\end{array}$ \\
\hline
\end{tabular}

* Results are from work conducted in Ref. 10 . Conversion from $x$ to $\Delta w t$ assumes density of amorphous silica at $1200^{\circ} \mathrm{C}(2.2$ $\left.\mathrm{g} / \mathrm{cm}^{7}\right)$ and density of cristobalite at $1300^{\circ}$ and $1400^{\circ} \mathrm{C}\left(2.32 \mathrm{~g} / \mathrm{cm}^{3}\right)$. ${ }^{ \pm}$Uncertainties reported for oxide thicknesses are $1 \sigma$ for at least 20 measurements at $1 \mathrm{~mm}$ spacing along SiC/oxide cross section. "Only data obtained in fused quartz reaction tubes are shown.

Table III. Parabolic Oxidation Rate Constant, $k_{\mathrm{p}}$, Determined from the Paralinear Oxidation of $\mathrm{SiC}$ in $50 \% \mathrm{H}_{2} \mathrm{O} / 50 \% \mathrm{O}_{2}$ Compared to Other Studies

\begin{tabular}{|c|c|c|c|}
\hline \multicolumn{4}{|c|}{$k_{\mathrm{p}}\left(\mathrm{mg}^{2} /\left(\mathrm{cm}^{4} \cdot \mathrm{h}\right)\right)$} \\
\hline $\begin{array}{l}\text { Temp } \\
\left({ }^{\circ} \mathrm{C}\right)\end{array}$ & $\begin{array}{l}50 \% \mathrm{H}_{2} \mathrm{O} / 50 \% \mathrm{O}_{2} \\
\text { (this study) }\end{array}$ & $\begin{array}{c}50 \% \mathrm{H}_{2} \mathrm{O} / 50 \% \mathrm{O}_{2} \\
\text { (Ref. 12) }\end{array}$ & $\begin{array}{c}5 \times k_{\mathrm{r}}\left(10 \% \mathrm{H}_{2} \mathrm{O} / 90 \% \mathrm{O}_{2}\right) \\
\text { (Ref. 10) }\end{array}$ \\
\hline 1200 & $\begin{array}{l}(3.80 \pm 0.06) \times 10^{-3} \\
(2.72 \pm 0.02) \times 10^{-3}\end{array}$ & $\begin{array}{l}1.14 \times 10^{-3} \\
1.27 \times 10^{-3} \\
1.28 \times 10^{-3} \\
1.05 \times 10^{-3}\end{array}$ & $\begin{array}{l}1.46 \times 10^{-3} \\
1.55 \times 10^{-3} \\
1.65 \times 10^{-3}\end{array}$ \\
\hline 1300 & $\begin{array}{l}(1.37 \pm 0.02) \times 10^{-3} \\
(1.57 \pm 0.03) \times 10^{-3} \\
(4.21 \pm 0.02) \times 10^{-3}\end{array}$ & $\begin{array}{l}1.85 \times 10^{-3} \\
1.72 \times 10^{-3} \\
2.08 \times 10^{-3}\end{array}$ & $\begin{array}{l}1.98 \times 10^{-3} \\
2.05 \times 10^{-3} \\
1.53 \times 10^{-3}\end{array}$ \\
\hline 1400 & $\begin{array}{l}(3.93 \pm 0.06) \times 10^{-3} \\
(5.57 \pm 0.04) \times 10^{-3}\end{array}$ & $\begin{array}{l}2.05 \times 10^{-3} \\
2.29 \times 10^{-3} \\
1.86 \times 10^{-3}\end{array}$ & $\begin{array}{l}1.79 \times 10^{-3} \\
1.63 \times 10^{-3} \\
1.73 \times 10^{-3}\end{array}$ \\
\hline
\end{tabular}

A sample TGA curve for each type of experiment as well as the fitted curves are shown in Figs. 4 through 6 . The linear rate constants determined by all three techniques are summarized in Table IV and plotted in Fig. 7. The linear volatilization constants measured for the fused quartz coupons and determined from the fit of the $\mathrm{SiC}$ paralinear data to the model equation are in terms of $\mathrm{mg} \mathrm{SiO}_{2} /\left(\mathrm{cm}^{2} \cdot \mathrm{h}\right)$, whereas the linear volatilization constant measured for the preoxidized $\mathrm{SiC}$ coupons is actually in $\mathrm{mg} \mathrm{SiC} /\left(\mathrm{cm}^{2} \cdot \mathrm{h}\right)$, since the oxide thickness remains nearly constant. In Fig. 7 , the linear volatilization constants from the fused quartz coupons and the paralinear fits have been multiplied by $\mathrm{MW}_{\mathrm{SiC}} / \mathrm{MW}_{\mathrm{SiO}}$, so that all volatility rates are expressed in $\mathrm{mg} \mathrm{SiC} /\left(\mathrm{cm}^{2} \cdot \mathrm{h}\right)$ and a direct comparison between the three techniques can be made. While there is some scatter, 


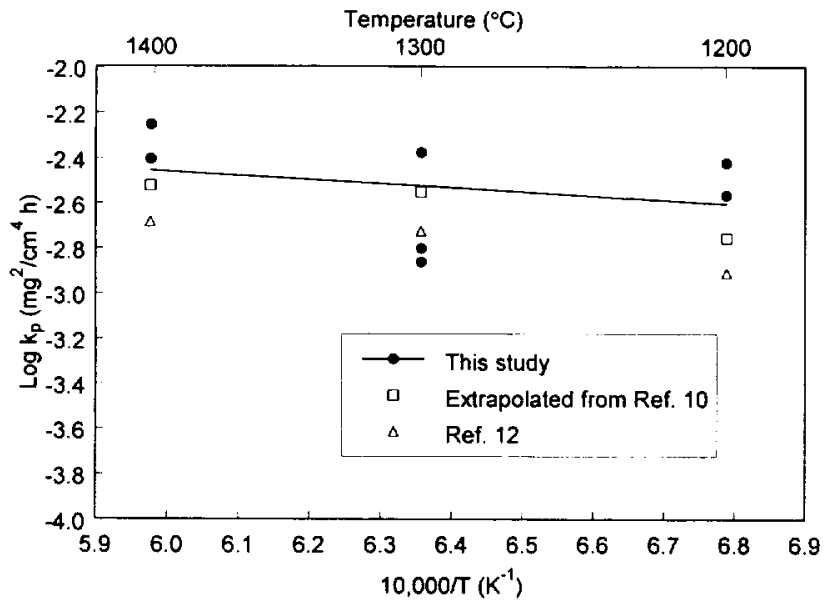

Fig. 3. Summary of parabolic oxide growth rates experimentally determined from the paralinear oxidation of $\mathrm{SiC}$. The solid line is the linear regression result for the experimental results of this study only. Data from Refs. 10 and 12 are shown for comparison.

the three techniques give similar results for the linear volatilization of $\mathrm{SiC}$ in water vapor. The mass flux of $\mathrm{SiC}$ has also been calculated as a function of temperature between $1200^{\circ}$ and $1400^{\circ} \mathrm{C}$ using Eq. (13), assuming $\mathrm{Si}(\mathrm{OH})_{4}(\mathrm{~g})$ is the volatile species and using vapor pressures calculated from the equilibrium constant for $\mathrm{Si}(\mathrm{OH})_{4}$ formation from Hashimoto ${ }^{17}$ to determine $\rho$. In both Eqs. (13) and (14), $J=k_{1}\left(\mathrm{MW}_{\mathrm{Si}_{(\mathrm{OH})}} / \mathrm{MW}_{\mathrm{SiO}_{2}}\right)$. There is good agreement between the experimentally determined values and those calculated based on Hashimoto's data. These types of calculations are often accurate only to within an order of magnitude.

The temperature dependence of the linear volatilization constant is very low. An activation energy of $3 \pm 75 \mathrm{~kJ} / \mathrm{mol}(95 \%$ confidence interval) was obtained in this study. Though the uncertainty is large, this result is not statistically significantly different from the value of $57 \pm 2 \mathrm{~kJ} / \mathrm{mol}$ reported by Hashimoto ${ }^{17}$ for the enthalpy of formation of $\mathrm{Si}(\mathrm{OH})_{4}$.

The thickness of the oxide on preoxidized SiC coupons was measured after the second exposure in the $50 \%$ water vaporcontaining environment. Typically, the oxide layer grew in thickness by an average of $9 \%$ (range $=-18 \%$ to $+48 \%$ ) in this 100 -hour exposure, while a weight loss was always observed, averaging $0.25 \mathrm{mg} / \mathrm{cm}^{2}$ (range $=0.13$ to $0.36 \mathrm{mg} / \mathrm{cm}^{2}$ ). The scatter in weight loss and scale thickness was independent of temperature.

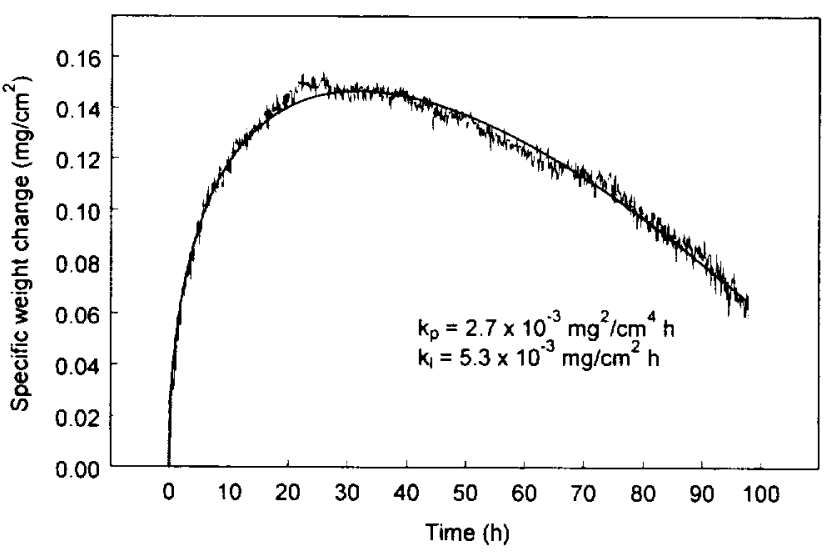

Fig. 4. Experimentally determined paralinear weight change kinetics for as-received $\mathrm{SiC}$ at $1200^{\circ} \mathrm{C}$ in $50 \% \mathrm{H}_{2} \mathrm{O} / 50 \%$ O flowing at $4.4 \mathrm{~cm} / \mathrm{s}$. The solid curve is the sum of $\Delta w_{1}$ and $\Delta w_{2}$ given by Eqs. (7) and (8) for $k_{\mathrm{p}}$ and $k_{1}$ determined by nonlinear least-squares analysis of the experimental data.

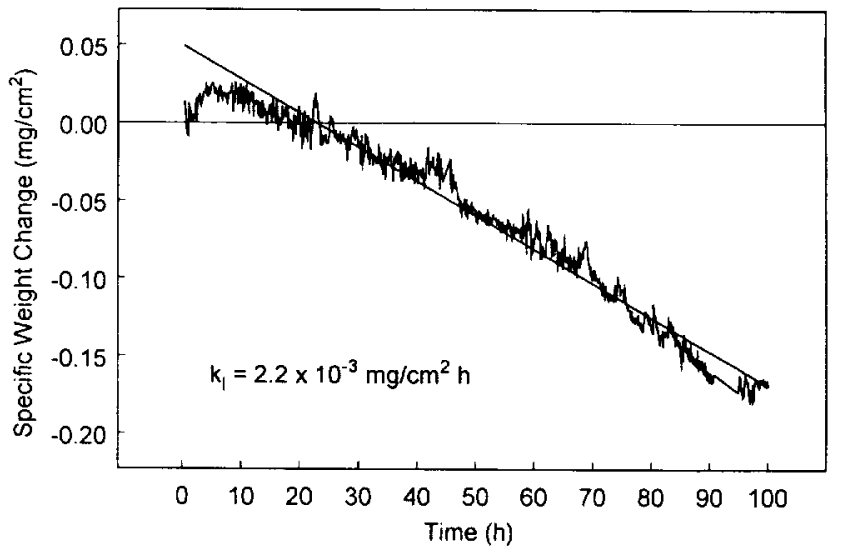

Fig. 5. Linear volatility of bulk silica at $1200^{\circ} \mathrm{C}$ in $50 \% \mathrm{H}_{2} \mathrm{O} / 50 \% \mathrm{O}_{2}$ flowing at $4.4 \mathrm{~cm} / \mathrm{s}$. The solid line shows the volatility rate determined by linear least-squares analysis of the experimental data.

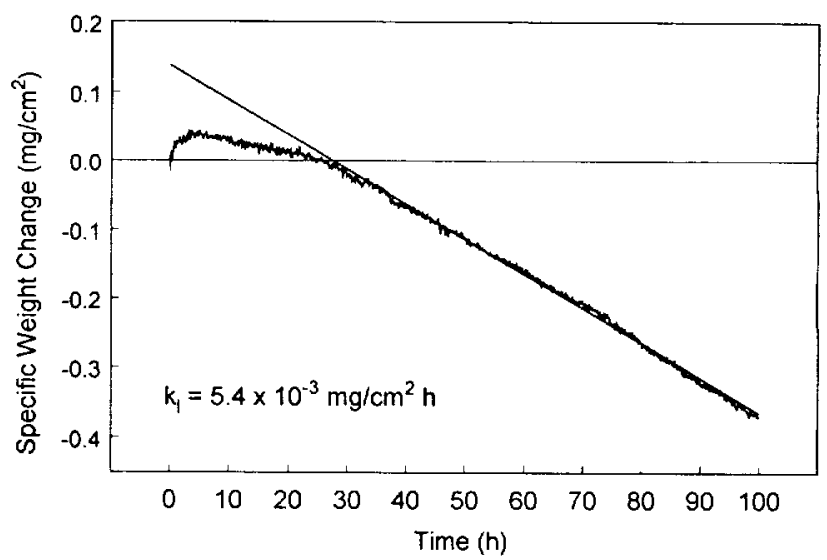

Fig. 6. Linear volatility of preoxidized $\mathrm{SiC}$ at $1200^{\circ} \mathrm{C}$ in $50 \% \mathrm{H}_{2} \mathrm{O}$ / $50 \% \mathrm{O}_{2}$ flowing at $4.4 \mathrm{~cm} / \mathrm{s}$. The initial oxide thickness for this test coupon was about $8 \mu \mathrm{m}$. The solid line shows the volatility rate determined by linear least-squares analysis of the experimental data after $30 \mathrm{~h}$.

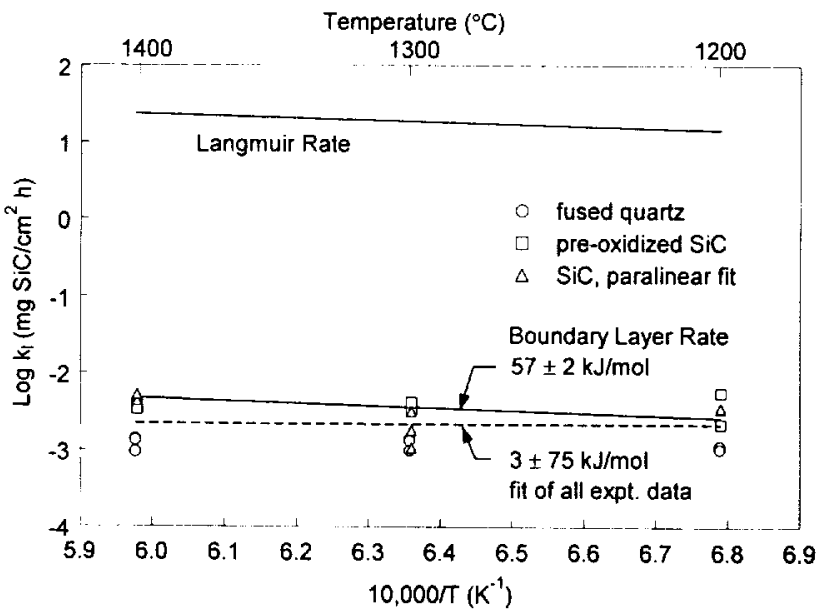

Fig. 7. Summary of linear volatilization rates for $\mathrm{SiC}$ in $50 \% \mathrm{H}_{2} \mathrm{O}$ / $50 \% \mathrm{O}_{2}$ at $4.4 \mathrm{~cm} / \mathrm{s}$. The solid lines are calculated from Eqs. (13) and (14) for the experimental conditions. The dotted line is the linear regression result for the experimental data (all three methods). 
Table IV. Experimentally Determined Values for the Linear Volatilization Rate Constant, $k_{1}$, in $50 \% \mathrm{H}_{2} \mathrm{O} / 50 \% \mathrm{O}_{2}$ at $4.4 \mathrm{~cm} / \mathrm{s}$

\begin{tabular}{cccc}
\hline $\begin{array}{c}\text { Temp } \\
\left({ }^{\circ} \mathrm{C}\right)\end{array}$ & $\begin{array}{c}\text { Paralinear oxidation of SiC } \\
\left(\mathrm{mg} \mathrm{SiO}_{2} /\left(\mathrm{cm}^{2} \cdot \mathrm{h}\right)\right)\end{array}$ & $\begin{array}{c}\text { Linear volatility of } \\
\text { fused quartz } \\
\left(\mathrm{mg} \mathrm{SiO}_{2} /\left(\mathrm{cm}^{2} \cdot \mathrm{h}\right)\right)\end{array}$ & $\begin{array}{c}\text { Linear volatility of } \\
\text { preoxidized SiC } \\
\left(\mathrm{mg} \mathrm{SiC} /\left(\mathrm{cm}^{2} \cdot \mathrm{h}\right)\right)\end{array}$ \\
\hline 1200 & $(5.05 \pm 0.06) \times 10^{-3}$ & $1.69 \times 10^{-3}$ & $5.43 \times 10^{-3}$ \\
& $(5.27 \pm 0.03) \times 10^{-3}$ & $1.55 \times 10^{-3}$ & $2.16 \times 10^{-3}$ \\
\multirow{2}{*}{1300} & $(1.60 \pm 0.04) \times 10^{-3}$ & $1.97 \times 10^{-3}$ & $3.33 \times 10^{-3}$ \\
& $(2.68 \pm 0.04) \times 10^{-3}$ & $2.07 \times 10^{-3}$ & $4.13 \times 10^{-3}$ \\
& $(5.07 \pm 0.02) \times 10^{-3}$ & $1.47 \times 10^{-3}$ & \\
\multirow{2}{*}{1400} & $(6.41 \pm 0.06) \times 10^{-3}$ & $2.00 \times 10^{-3}$ & $3.76 \times 10^{-3}$ \\
& $(7.75 \pm 0.04) \times 10^{-3}$ & $2.07 \times 10^{-3}$ & $3.32 \times 10^{-3}$ \\
\hline
\end{tabular}

\section{(3) Scale Characterization}

The crystallinity of the oxide scale increased with temperature as shown in Fig. 8 . The scales at $1200^{\circ} \mathrm{C}$ were still completely amorphous (within the sensitivity of XRD) even after $100 \mathrm{~h}$ exposures in $50 \%$ water vapor. While this temperature dependence was expected, a surprising result was that the amount of crystallinity was no different than that found in dry oxygen under the same conditions. ${ }^{30}$ There are many references in the literature that state that water vapor increases the crystallization rate of silica (summarized in Ref. 12).

Typical SEM surface morphologies are shown in Fig. 9. Some bubbles are visible in the scale at $1200^{\circ} \mathrm{C}$. Note the absence of cracks in the scale, indicating the scale is amorphous in agreement with the XRD results. The spherulitic structure and cracks in the scale progressively increased with temperature at $1300^{\circ}$ and $1400^{\circ} \mathrm{C}$. Cracks in the scale are due to the $\beta$-to- $\alpha$ transformation of cristobalite on cooling. While bubbles are no longer found, irregularly shaped pores are now observed.

\section{Discussion}

\section{(1) Scale Growth}

The value for the parabolic oxidation rate constant determined from the paralinear equation represents the oxide growth rate that would be observed in the absence of silica volatility at that same temperature and water vapor partial pressure. The results pertaining to the parabolic rate constant as well as the scale morphology will be discussed in full elsewhere. ${ }^{12}$ Preliminary results indicate that the parabolic rate constant is approximately proportional to $P\left(\mathrm{H}_{2} \mathrm{O}\right)$, indicating that scale growth in the absence of volatility is controlled by molecular diffusion of water vapor in silica." "The amount of crystalline phase appeared to be independent of the presence of water vapor. The origin of

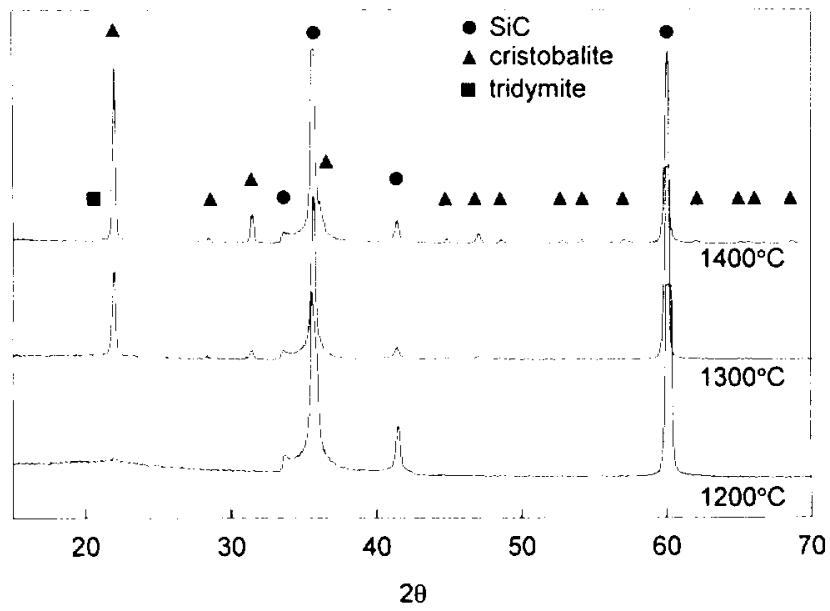

Fig. 8. X-ray diffraction spectra for $\mathrm{SiC}$ oxidized for $100 \mathrm{~h}$ in $50 \% \mathrm{H}_{2} \mathrm{O} / 50 \% \mathrm{O}_{2}$ as a function of temperature. bubbles in the amorphous scale may be due to the increased pressures of gaseous reaction products formed by the accelerated oxidation reaction in water vapor. These bubbles were observed only in amorphous scales, probably due to the decreased viscosity of amorphous silica containing high amounts of water. ${ }^{31}$ These comments on the bubbles are only speculation at this point, and further discussion will be left to a future publication. $^{12}$

\section{(2) Paralinear Oxidation}

The first indication that paralinear kinetics are followed for $\mathrm{SiC}$ in $50 \% \mathrm{H}_{2} \mathrm{O}$ vapor came from the discrepancy between the measured $\Delta w t$ and the $\Delta w t$ predicted from the measured oxide thickness. In all the $50 \%$ water vapor exposures, there is not enough weight gain to account for the amount of oxide found on the surface, even though the loss of $\mathrm{C}$ as $\mathrm{CO}$ is already accounted for. Therefore, some weight loss must be due to loss of silicon. Additional evidence for the volatility of the silica scale is the deposition of silicon- and oxygen-containing material on cooler surfaces in the reaction tube and on the sample hanger. The shape of the $100 \mathrm{~h}$ TGA curves themselves, while not exhibiting the long-term linear weight losses characteristic of paralinear behavior, do show the initial stages of paralinear kinetics: a significant leveling off of the weight gain or a maximum in the weight gain is observed after 30 to $40 \mathrm{~h}$. Experiments to times approaching the limiting oxide thickness (on the order of $1000 \mathrm{~h}$ ) were not possible, due to limitations in the water vapor saturation system. Proof of silica scale volatility comes from the linear weight losses observed for preoxidized $\mathrm{SiC}$ with thick silica scales and the agreement of these rates with those found for volatility of bulk silica.

The question may be asked why wasn't any evidence of this paralinear behavior previously observed for silica-forming materials? Much of the previous work (summarized in Ref. 10) was conducted for short times, less than $30 \mathrm{~h}$, in which the linear volatilization is overwhelmed by the parabolic oxidation of SiC. Secondly, in previous studies, impurity effects were not isolated from water vapor effects. Impurities enhance the parabolic oxidation rate of $\mathrm{SiC}^{30}$ but are expected to have little effect on a boundary-controlled volatilization rate. By examining Eqs. (7) and (8), it can be seen that an increase in $k_{\mathrm{p}}$ with a constant $k_{1}$ would increase the time at which the maximum in weight gain occurs. Volatility effects on the weight change would be more difficult to observe under these conditions. Finally, many of the earlier investigations were also conducted in low partial pressures of water vapor $(\approx 3 \%$ to $\left.10 \% \mathrm{H}_{2} \mathrm{O}\right)$ at low gas velocities $(\approx 0.4 \mathrm{~cm} / \mathrm{s})$ where volatility is not observed.

However, there were some hints that volatility of the silica scale would be important under the conditions studied here. Ligenza ${ }^{20}$ observed the solubility of the oxide formed on silicon in the stream under a variety of conditions, for example, $650^{\circ} \mathrm{C}$, $75 \mathrm{~atm}, 2 \mathrm{~h}$. Deal ${ }^{21}$ found that in wet oxygen $\left(85 \% \mathrm{H}_{2} \mathrm{O}\right)$ and steam at $1 \mathrm{~atm}$ total pressure the amount of silica formed on silicon after $4 \mathrm{~h}$ was less than that expected from the amount of silicon consumed. This was attributed to the erosion of the 

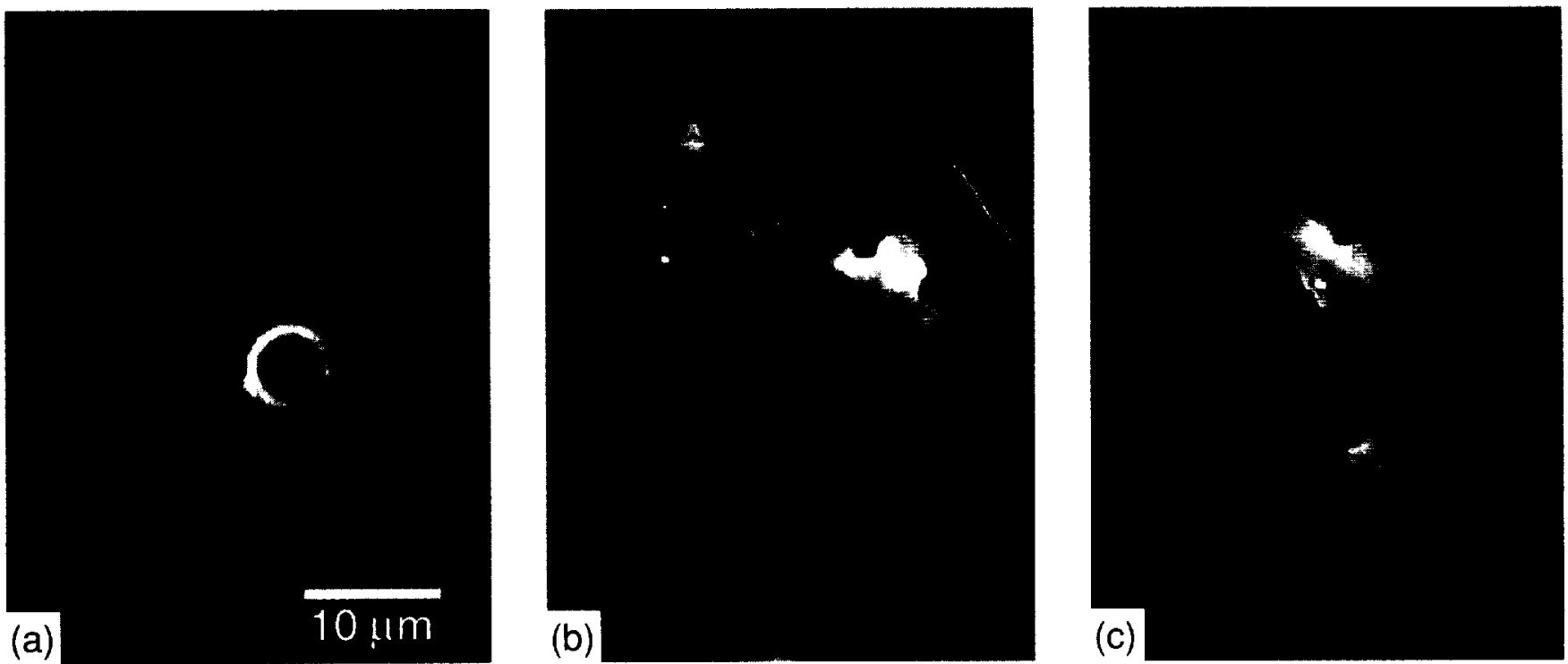

Fig. 9. Scanning electron micrographs showing the oxide surface morphology of CVD SiC oxidized in $50 \% \mathrm{H}_{2} \mathrm{O} / 50 \% \mathrm{O}_{2}$ for $100 \mathrm{~h}$ as function of temperature: (a) $1200^{\circ} \mathrm{C}$, (b) $1300^{\circ} \mathrm{C}$, and (c) $1400^{\circ} \mathrm{C}$.

oxide in the wet oxidizing atmospheres. The mechanism of erosion was not determined, nor was the rate of erosion quantified. Choi et $a l^{32}$ observed that "parabolic rate constants" for $\mathrm{Si}_{3} \mathrm{~N}_{4}$ calculated from oxide thicknesses after exposure in water vapor at $1100^{\circ}$ to $1200^{\circ} \mathrm{C}$ for times around $10 \mathrm{~h}$ and less actually decreased with water contents over $40 \%$ to $60 \%$. This behavior may be due to paralinear oxidation rather than the blocking effect of the $\mathrm{NO}$ or $\mathrm{NH}_{3}$ reaction products proposed by the authors. Silicon nitride may show paralinear behavior at shorter times, since the parabolic oxidation rate is much lower than that of $\mathrm{SiC}$. Paralinear kinetics for $\mathrm{Si}_{3} \mathrm{~N}_{4}$ have not yet been studied.

Since the conditions of this study most closely match the conditions studied by Hashimoto ${ }^{17}$ (i.e., 1 atm total pressure $\mathrm{H}_{2} \mathrm{O} / \mathrm{O}_{2}$ mixtures, $P\left(\mathrm{H}_{2} \mathrm{O}\right)$ varying between 0.1 and $0.6 \mathrm{~atm}$, $T=1100^{\circ}$ to $1500^{\circ} \mathrm{C}$ ), it was assumed throughout this study that $\mathrm{Si}(\mathrm{OH})_{4}$ is the major volatile species. Preliminary mass spectrometric results obtained for $\mathrm{SiO}_{2}$ at 1 atm total pressure, $90 \%$ to $95 \% \mathrm{H}_{2} \mathrm{O}$ in $\mathrm{O}_{2}$, and $1300^{\circ} \mathrm{C}$ confirm the presence of this vapor species. ${ }^{18}$ As mentioned in the Results section, there is relatively good agreement between the linear volatilization constants determined by the three experimental methods and the values calculated for $\mathrm{Si}(\mathrm{OH})_{4}$ volatility using Hashimoto's data. This agreement supports the assumption that $\mathrm{Si}(\mathrm{OH})_{4}$ is the volatile species formed under the conditions of this study.

The formation of volatile species from the fused quartz reaction tube apparently did not saturate the gas stream. If the fused quartz tubes at least partially saturated the gas stream and suppressed volatilization of the test coupon, then the experimental linear weight loss rates would be less than those calculated based on the boundary layer equation under nonsaturated conditions.

The nonlinearity in weight loss observed at the beginning of the exposures of the preoxidized $\mathrm{SiC}$ coupons may be due to sealing of cracks and imperfections in the thick oxide scale which were observed by SEM after preoxidation. After irregularities in the scale are healed, only linear volatility would be observed. A limiting oxide thickness calculated from all $k_{\mathrm{p}}$ and $k_{1}$ results at $1200^{\circ} \mathrm{C}$ in Tables III and IV give a limiting oxide thickness of $6.9 \mu \mathrm{m}$. Preoxidized samples had oxidized thicknesses of 6 to $8 \mu \mathrm{m}$, which is close to the limiting oxide thickness expected. Therefore, $9 \%$ growth in oxide thicknesses during subsequent $100 \mathrm{~h}$ exposures in $\mathrm{H}_{2} \mathrm{O} / \mathrm{O}_{2}$ indicates growth is minimal, as would be expected for scales near the limiting oxide thickness.

The volatilization rates and activation energies did not depend on the crystallinity of the silica scale. The volatility rates of two fused quartz coupons were measured, one in an alumina tube (coupon crystallizes in a few hours) and in a fused quartz tube (coupon remains amorphous) at $1200^{\circ} \mathrm{C}$ for $100 \mathrm{~h}$ The volatility rates were within a factor of 2 of each other. This is the same magnitude of variability found in exact repeat experiments. Even if the reaction rates for water with amorphous and crystalline silica differed, no difference in volatility rates would be expected for a boundary layer-controlled process.

\section{(3) Combustor Applications and Life Predictions}

The implications of this study for the long-term chemical durability of $\mathrm{SiC}$ in combustion environments will now be addressed. First, of most importance, is the conclusion that the volatility of silica controls the lifetime of any $\mathrm{SiC}$ component. At long times (on the order of hundred hours), a steady state should be achieved in which a constant thickness of oxide exists on the $\mathrm{SiC}$. The oxidation of $\mathrm{SiC}$ then proceeds linearly at the same rate that the silica volatilizes. The $\mathrm{SiC}$ surface recession also occurs at a linear rate. The only influence of the parabolic oxidation rate constant, $k_{\mathrm{p}}$, on this behavior is to establish the limiting thickness of the oxide layer which recedes into the $\mathrm{SiC}$. For long-term applications, the recession rate of $\mathrm{SiC}$ can therefore be approximated using the linear rate constant alone. This has also been demonstrated for other paralinear processes such as alumina formation and spallation on $\mathrm{NiAl}{ }^{33}$

The effect of the relative temperature dependence of the rate constants on scale growth should also be considered. Because the activation energy for oxidation is greater than that for volatilization, the limiting oxide thickness should increase with temperature. An additional point is that silica volatility will be a problem even at the lower application temperatures of $\mathrm{SiC}$ $\left(1200^{\circ} \mathrm{C}\right.$ and below). As the temperature is lowered, the oxidation rate would decrease compared to the volatility rate. At some point, paralinear kinetics would no longer apply. SiC oxidation would be dominated by linear oxidation kinetics due to the thinness of the oxide layers formed. The oxidation/ volatilization reaction kinetics under these conditions would be described as the summation of two linear processes. ${ }^{6}$

Given a recession rate goal, extrapolations of the results from this paper can be made to predict lifetimes of $\mathrm{SiC}$ in real applications. The paralinear behavior observed at short times is assumed to be negligible for the long-term lifetime of $\mathrm{SiC}$ in water vapor-containing environments. Thus, Eq. (13) can be used to predict the $\mathrm{SiC}$ recession rate for long times. Equation (13) can also be reduced to a simple relationship between the mass 
flux, $k_{1}$, and process variables such as water vapor partial pressure, total pressure, and gas velocity. The temperature dependence is not included in this relationship, first, because the results from this study were conducted at typical desired use temperatures of $\mathrm{SiC}$ so no temperature extrapolations are needed, and second, the temperature dependence was found to be minimal. The velocity dependence of the flux is clearly $v^{1 / 2}$; however, the pressure dependence is more complex. The diffusion coefficient, $D$, is proportional to $1 / P_{\text {total }}, \rho^{\prime} \propto P_{\text {total }}$, and, assuming $\mathrm{Si}(\mathrm{OH})_{4}$ is the volatile species, according to Eq. (4), $\rho \propto P\left(\mathrm{H}_{2} \mathrm{O}\right)^{2}$. The resulting simplified relationship is

$$
k_{1} \propto \frac{v^{1 / 2} P\left(\mathrm{H}_{2} \mathrm{O}\right)^{2}}{P_{\text {total }}^{1 / 2}}
$$

Under combustion conditions, for example: $T=1200^{\circ} \mathrm{C}$, $P_{\text {tolal }}=10 \mathrm{~atm}, P\left(\mathrm{H}_{2} \mathrm{O}\right)=1 \mathrm{~atm}$, and gas velocity $=3000 \mathrm{~cm} / \mathrm{s}$, the volatility rate would be about 33 times greater than determined in this study. In addition, these calculations were based on laminar flow conditions limited by diffusion through a gas boundary layer. The Reynolds number (for flow in a smooth pipe geometry) for the combustion conditions above is about $3 \times 10^{4}$, which is greater than 2100 where the transition to turbulent flow begins. ${ }^{34}$ Therefore, the actual combustion conditions may be turbulent. The estimated volatility rates based on Eqs. (13) or (17) serve as a lower bound. The volatility rate calculated from the Langmuir equation, Eq. (14), for vaporization in a perfect vacuum can serve as an upper bound. For example, this upper bound is shown in Fig. 7 for the $1 \mathrm{~atm}$ conditions studied here. Actual volatilization rates will fall between these two bounds, depending on the turbulent conditions.

Mass fluxes can easily be converted to $\mathrm{SiC}$ recession rates using the density of $\mathrm{SiC}\left(\approx 3.2 \mathrm{~g} / \mathrm{cm}^{3}\right)$. Using the average $k_{1}$ from this study from all temperatures between $1200^{\circ}$ and $1400^{\circ} \mathrm{C}$, about $2.5 \times 10^{-3} \mathrm{mg} /\left(\mathrm{cm}^{2} \cdot \mathrm{h}\right)$, extrapolated to the combustion conditions above, a recession rate of $2.6 \times 10^{-5} \mathrm{~cm} / \mathrm{h}$ is calculated, assuming laminar flow. Recession rates would be greater in the case of turbulent flow. Lifetimes of SiC components in combustion environments can then be computed based on the maximum acceptable amount of component recession. The volatility of silica scales on $\mathrm{SiC}$ in combustion environments is clearly a concern for thin components.

\section{Conclusions}

It has been demonstrated that $\mathrm{SiC}$ undergoes paralinear oxidation/volatilization reactions in an environment containing $50 \% \mathrm{H}_{2} \mathrm{O} / 50 \%$ oxygen at $1 \mathrm{~atm}$ total pressure and temperatures between $1200^{\circ}$ and $1400^{\circ} \mathrm{C}$. Based on this work, the results of Hashimoto, ${ }^{17}$ and preliminary atmospheric mass spectrometry results, ${ }^{18}$ it is believed that the silica scale volatilizes as an $\mathrm{Si}(\mathrm{OH})_{4}(g)$ species. Because the volatility of silica in water vapor controls the recession rate of $\mathrm{SiC}$, lifetimes of $\mathrm{SiC}$ based on a component thickness criterion can be predicted based on the linear volatilization rate of $\mathrm{SiO}_{2}$ alone. Extrapolations to hypothetical combustion conditions have shown that the lifetime of thin $\mathrm{SiC}$ components in some combustion environments are inadequate for long-term applications.

Acknowledgment: The authors would like to thank Ralph Garlick of NASA-Lewis Research Center for the X-ray diffraction results.

\section{References}

'N S. Jacobson, "Corrosion of Silicon-Based Ceramics in Combustion Environments," J. Am. Ceram. Soc., 76 [1] 3-28 (1993).
${ }^{2}$ W. A. Sanders and J. R. Johnston, "High Velocity Burner Rig Oxidation and Thermal Fatigue Behavior of $\mathrm{Si}_{3} \mathrm{~N}_{4}$ - and $\mathrm{SiC}$-Base Ceramics to $1370^{\circ} \mathrm{C}$, , NASA TM 79040, 1978.

J. D. Cawley and R. F. Handschuh, "Phenomenological Study of the Behavior of Some Silica Formers in a High Velocity Jet Fuel Bumer." NASA TM 87127. 1985.

${ }^{4}$ L. J. Lindberg, "Durability Testing of Ceramic Materials for Turbine Engine Applications"; pp. 149-61 in Proceedings of the 24th Automotive Technology Development Contractors' Coordination Meeting (Dearborn, MI. Oct. 27-30. 1986). Society of Automotive Engineers, Warrendale, PA, 1987

${ }^{5}$ E. L. Brady, "Chemical Nature of Silica Carried by Steam," J. Phys. Chem., 57, 706-10 (1953).

${ }^{6}$ E. J. Opila and N. S. Jacobson, "SiO(g) Formation from $\mathrm{SiC}$ in Mixed Oxidizing/Reducing Gases," Oxid. Met, 44 |5/6] 527-44 (1995).

${ }^{7}$ C. S. Tedmon Jr.. "The Effect of Oxide Volatilization on the Oxidation Kinetics of $\mathrm{Cr}$ and $\mathrm{Fe}-\mathrm{Cr}$ Alloys," J. Electrochem. Soc. 113 [8] 766-68 (1967).

"J. A. Costello and R. E. Tressler, "Oxidation Kinetics of Silicon Carbide Crystals and Ceramics: I, In Dry Oxygen," I. Am. Ceram. Soc., 69 [9] 67481 (1986).

${ }^{4}$ L. U. J. T. Ogbuji and E. J. Opila, "A Comparison of the Oxidation Kinetics of $\mathrm{SiC}$ and $\mathrm{Si}_{3} \mathrm{~N}_{4}$, J. Electrochem. Soc., 142 [3] 925-30 (1995).

${ }^{10} \mathrm{E}$. J. Opila, "Oxidation Kinetics of Chemically Vapor-Deposited Silicon Carbide in Wet Oxygen," J. Am. Ceram. Soc., 77 [3] 730-36 (1994).

"B. E. Deal and A. S. Grove, "General Relationship for the Thermal Oxidation of Silicon," J. Appl. Phys., 36 [12] 3770-78 (1965)

${ }^{12} \mathrm{E}$. J. Opila, "The Variation of the Oxidation Rate of $\mathrm{SiC}$ with Water Vapor Pressure," unpublished work.

"H.-E. Kim and D. W. Readey, "Active Oxidation of SiC in Low Dew-Poin Hydrogen above $1400^{\circ} \mathrm{C}$ '; pp. $301-12$ in Silicon Carbide '87. Edited by J. D. Cawley and C. E. Semler. American Ceramic Society, Westerville, OH, 1987.

${ }^{4}$ T. Narushima, T. Goto, Y. Yokoyama, Y. lguchi, and T. Hirai, "HighTemperature Active Oxidation of Chemically Vapor-Deposited Silicon Carbide in $\mathrm{CO}-\mathrm{CO}_{2}$ Atmosphere," J. Am. Ceram. Soc., 76 [10] 2521-24 (1993).

"O. Glemser and H. G. Wendlandt, "Gaseous Hydroxides"; pp. $215-58$ in Advances in Inorganic Chemistry and Radiochemistry, Vol. 5. Edited by H. J. Emeléus and A. G. Sharpe. Academic Press, New York, 1965

${ }^{11}$ M.-C. Cheng and I. B. Cutler, "Vaporization of Silica in Steam Atmosphere," J. Am. Ceram. Soc., 62 [1]-12] 593-96(1979).

${ }^{17}$ A. Hashimoto, "The Effect of $\mathrm{H}_{2} \mathrm{O}$ Gas on Volatilities of Planet-Forming Major Elements: I. Experimental Determination of Thermodynamic Properties of $\mathrm{Ca}-, \mathrm{Al}-$, and Si-hydroxide Gas Molecules and Its Application to the Solar Nebula." Geochim. Cosmochim. Acta, 56, 511-32 (1992).

${ }^{18}$ E. J. Opila, D. S. Fox, and N. S. Jacobson, "Mass Spectrometric Identification of Si-O-H $(\delta)$ Species from the Reaction of Silica with Water Vapor at Atmospheric Pressure," J. Am. Ceram. Soc., in review.

${ }^{14}$ D. L. Hildenbrand and K. H. Lau, "Thermochemistry of $\mathrm{SiO}(\mathrm{OH}), \operatorname{SiO}(\mathrm{OH})_{2}$, and $\mathrm{SiO}_{2}, " J$. Chem. Phys., 101 [7] 6076-79 (1994).

${ }^{20} \mathrm{~J}$. R. Ligenza, "Oxidation of Silicon by High-Pressure Steam," I. Electrochem. Soc., 109 [2] 73-76 (1962).

'B. E. Deal, "The Oxidation of Silicon in Dry Oxygen, Wet Oxygen, and Steam," J. Electrochem. Soc., 110 [6] 527-33 (1963).

'W. H. Press, S. A. Teukolsky, W. T. Vetterling, and B. P. Flannery, Numerical Recipes in $C, 2$ nd ed; pp. 683-98. Cambridge University Press, Cambridge, U.K., 1992.

B. Efron, "Computers and the Theory of Statistics: Thinking the Unthinkable," SIAM Re1., 21 [4] 460-80 (1979).

${ }^{24}$ E. D. Feigelson and G. J. Babu, "Linear Regression in Astronomy II. Coma Cluster; Virgo Cluster; Abell 1656," Astrophys. J., 397 [1] 55-67 (1992)

${ }^{25}$ K. G. Hayes, M. L. Perl, and B. Efron, "Application of the Bootstrap Statistical Method to the Tau-Decay-Mode Problem," Phys. Rev. D, 39 [1] $274-$ $79(1989)$

${ }^{26} \mathrm{~S}$. B. Crary and D. A. Fahey "Analysis of Critical-Exponent Data Using Efron's Bootstrap Technique," Phys. Rev. B: Condens. Matter, 35 |4| 2102104 (1987).

${ }^{27}$ W. M. Kays and M. E. Crawford, Convective Heat and Mass Transfer, 2nd ed; p. 139. McGraw-Hill, New York, 1980

${ }^{2}$ G. H. Geiger and D. R. Poirier, Transport Phenomena in Metallurgy: p. 464. Addison-Wesley, Reading, MA, 1973.

${ }^{24}$ R. A. Svehla, "Estimated Viscosities and Themal Conductivities of Gases at High Temperatures," NASA Technical Report R-132.

"E. J. Opila, "The Influence of Reaction Tube Impurities on the Oxidation of CVD SiC," J. Am. Ceram. Soc., 78 [4] 1107-10 (1995).

"G. Heatherington. K. H. Jack, and J. C. Kennedy, "The Viscosity of Vitreous Silica" Phys Chem. Glass, 5 |5] 130-36 (1964)

${ }^{32}$ D. J. Choi, D. B. Fischbach, and W. D. Scott, "Oxidation of ChemicallyVapor-Deposited Silicon Nitride and Single-Crystal Silicon," I. Am. Ceram. Soc., 72 [7] 1118-23 (1989).

"J A Nesbitt and C. A Barrett "Predicting the Oxidation-Limited Lifetime of $\beta$-NiAl"; pp. 601-609 in Structural Intermetallics. Edited by R. Darolia, J. J. Lewandowski, C. T. Liu, P. L. Martin, D. B. Miracle, and M. V. Nathal. The Minerals, Metals, and Materials Society, Warrendale, PA, 1993.

${ }^{34} \mathrm{D}$. R. Gaskell, An Introduction to Transport Phenomena in Materials Engineering. Macmillan, New York, 1992. 
